\title{
José Bergamín y su dramaturgia en Francia ${ }^{1}$
}

\author{
Ma Teresa Santa María Fernández \\ GEXEL, Universidad Internacional de La Rioja
}

Título: José Bergamín y su dramaturgia en Francia.

Resumen: El teatro de José Bergamín durante su exilio en Francia abarca más de una década, entre 1954 y 1970. A lo largo de los mismos encontramos cuatro obras interesantes por tratar bien temas del Siglo de Oro -la Gatomaquia lopesca-, bien de la mitología griega - La sangre de Antígona y Donde una voz se apaga-; o girar alrededor de un poema de Baudelaire, La cama, tumba del sueño o El dormitorio. La relevancia de este autor de la llamada Generación del 27 en su estancia parisina se manifiesta, además, en las traducciones y obras suyas que se representaron durante esos años en Francia. Siempre con el objetivo puesto en su labor dramática, resulta interesante comprobar esa influencia en sus últimas producciones dramáticas, algunas de las cuales fueron escritas en francés.

Palabras clave: Teatro, José Bergamín, Exilio, Gatomaquia, Mitos.

Fecha de recepción: 17/11/2015.

Fecha de aceptación: 27/11/2015.
Title: José Bergamín and his Theater in France.

Abstract: José Bergamín's theater during his exile in France goes from 1954 to 1970. During these years, he wrote four interesting plays to talk about, with subjects found in the Spanish "Siglo de Oro" -the "lopesca" Gatomaquia-; from the Greek mythology La sangre de Antígona and Donde una voz se apaga-; or from Baudelaire's poem, La cama, tumba del sueño o El dormitorio. The relevance of this author of the Generation of the $27^{\text {th }}$ in his stay in Paris is also evident in the translations and performances during those years in France. It is interesting to see that influence in his last dramatic plays, some of them were even written in French.

Key words: Theater, José Bergamín, Exile, Gatomaquia, Myths.

Date of Receipt: 17/11/2015

Date of Approval: 27/11/2015.

1 Este trabajo se engloba dentro del proyecto La historia de la literatura española y el exilio republicano de 1939 (FFI2013-42431-P), cuyo investigador principal es Manuel Aznar Soler y del que es miembro investigador la autora del mismo. 
José Bergamín recaló tres veces en Francia durante su exilio. La primera estancia fue muy breve y ocurrió en 1939, camino de su destierro a México, a donde llegó ese mismo año; la segunda, de 1954 a 1958, con la idea de estar cerca y poder volver a España; y la tercera tras su expulsión de nuestro país en 1963, cuando tras casi dos meses en Montevideo, se instala de nuevo en París, donde vive "como un fantasma" en el palacio que, gracias a Malraux, el gobierno francés le proporcionó ${ }^{2}$.

Desde luego, nos interesa reseñar aquí solo esas dos últimas estancias en Francia, de 1954 a 1958 y de 1963 a 1970, por ser durante las mismas cuando publica algunas de las piezas que comentaremos o idea algunos temas de los que solo podemos reseñar su título y posible trama, ya que continúan inéditos y perdidos.

Durante el primer periodo reside como huésped de la Casa de México, dentro de la Cité Universitaire, y se reencuentra con viejos amigos, a través de dos tertulias diferentes: "una de habla hispana: Bacarisse, Ramón Gaya, Picasso, Gurméndez... y la venezolana Fina Gómez [...]. Por otra parte, Malraux, F. Delay, Claude Aveline, Pierre Emmanuel, quien le pone en contacto con los círculos intelectuales católicos de París"3. De esta época proceden también dos obras dramáticas, La sangre de Antígona y La cama, tumba del sueño o El dormitorio, fechadas en los años cincuenta, aunque no se publicaran hasta casi treinta años después, en la revista Primer Acto ${ }^{4}$. Pero también en este primer periodo terminaría Los tejados de Madrid o El amor anduvo a gatas, así como Donde una voz se apaga y otra se enciende, ambas iniciadas en su anterior país de exilio, Uruguay.

Es indudable que La sangre de Antígona corresponde a esta etapa de su primer exilio en Francia, ya que sabemos que el dramaturgo estuvo trabajando junto al músico Salvador Bacarisse sobre la citada pieza tea-

2 Para estas etapas del exilio de Bergamín en Francia, véase Gonzalo Penalva Candela, Tras las huellas de un fantasma. Aproximación a la vida y obra de José Bergamin, Madrid, Ediciones Turner, 1985, pp. 232-238.

3 Ibidem, p. 187.

4 José Bergamín, "La sangre de Antígona, La cama, tumba del sueño o El dormitorio", Primer Acto, Madrid, 198 (marzo-abril 1983), pp. 48-80. 
tral, dando por terminada la partitura en 1955, aunque el texto pudiera, tal vez, dilatarse un poco más ${ }^{5}$. Idéntica fecha se baraja para la creación de La cama, tumba de sueño pues, tal y como indica el dibujo que cierra la edición de Primer Acto, realizado por el propio Bergamín, la obra fue terminada en París, el 26 de junio de 1956. Además, su escritura durante sus años en París justificaría su elaboración a partir de un poema de Baudelaire y la constatación que aparece en Primer Acto de que "el original, en francés, Le lit tombeau du rêve ou la chambre a couclar, se inspira en el poema en prosa de Baudelaire, leído por el fantasma: La chambredouble"'. También encontramos en el texto publicado en la revista teatral ciertas oraciones en francés dentro de La sangre de Antígona, como "Evocation musicale (avec voix) de la bataille"7.

Por otro lado, en esta época debió de dar sus últimos retoques a lo que era mero proyecto en 1954, "una gatuna Zapaquilda, adaptación escénica de La Gatomaquia de Lope, homenaje mío al poeta" ${ }^{8}$, pues la obra se publicó, bajo el título de Los tejados de Madrid o El amor anduvo a gatas en 1961 en la revista Primer Acto ${ }^{9}$. La cuarta obra dramática relacionada con su exilio francés sería Donde una voz se apaga otra se enciende, Echo où es-tu, en la traducción francesa inédita de la que disponemos y donde aparece como fecha de creación el año de 1952.

En efecto, en las "Acotaciones a Medea" que aparecen, en 1954, en Marcha, Bergamín incluye una nómina de obras que nos parece interesante reproducir: "La muerte burlada, La hija de Dios, La niña guerrillera, Melusina... ya publicadas; y las proyectadas a medio escribir: ¿Adónde iré que no tiemble?, La voz de Eco, La San Bartolomé, Sor Abelardo..., y hasta una gatuna Zapaquilda, adaptación escénica de La

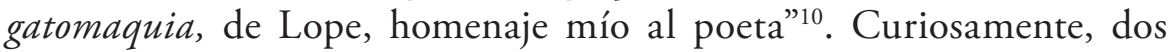

5 Christiane Heine, "Salvador Bacarisse en el Centenario de su nacimiento", Cuadernos de Música Iberoamericana, 5 (1998), pp. 43-75.

6 José Bergamín, "La cama, tumba del sueño", p. 70.

7 José Bergamín, "La sangre de Antígona”, p. 51.

8 Rogelio Martínez y Alicia Cagnasso (eds), Crónica del exilio de Bergamín en Uruguay, III: Teatro. Crítica. Polémicas. Crónicas de prensa. Testimonios. Reportajes, Montevideo, Ediciones Bergamín, 2004, p. 329.

9 José Bergamín, "Los tejados de Madrid o El amor anduvo a gatas", Primer Acto, Madrid (marzo 1961), pp. 23-39.

10 José Bergamín, "Acotaciones a Medea", Marcha, Montevideo, 714 (2 abril 1954), p. 
de estas obras teatrales, Donde una voz se apaga otra se enciende y $E l$ nuevo Abelardo, aparecen con otros títulos, La voz de Eco y Sor Aberlar$d o$, tanto en las nuevas "Acotaciones a Medea", que se incorporan a la edición de Primer Acto en 1961, como en el inventario de "Textos inacabados, perdidos o inéditos", que se incluye en el número homenaje que le dedicó la revista Cuadernos El Público ${ }^{11}$. Sin embargo, ninguno de los dos textos es mencionado en la entrevista que le realizó Carlos Gurméndez en 1980.

También de su segunda estancia, de 1964 a 1970, podemos dar una lista de proyectos y obras perdidas que incluirían títulos como La tiara de cascabeles, La barricada, "Las alas de la hormiga, una visión de la primavera de Praga, y El zángano que se creyó reina-abeja, sobre el Concilio Vaticano II y la figura del Papa"12. Por otro lado, en los dos números que Cuadernos El Público y Primer Acto dedicaron a la labor teatral de nuestro escritor se incluyen tres textos dramáticos más: El alma en un hilo, Arturo o el hijo del esqueleto y Los tiempos que corren ${ }^{13}$. Además, en una conversación con su amigo José Esteban, en marzo de 1981, reafirma su intención de sacar a la luz algunos de estos textos:

Ahora quiero hacer una serie de libelos ilegales, pero no clandestinos, que son cosas muy diferentes. Por ejemplo, El infamador. Limpia, fija $y$ da esplendor, y seguir publicando duendecitos y coplas y algunas de mis piezas teatrales de tiempos pasados y presentes, como La tiara de cascabeles, Las alas de la hormiga, El zángano que se creyó reina abeja, Rey ni llovido del cielo, y un largo etcétera ${ }^{14}$.

\section{Recogida en Rogelio Martínez y Alicia Cagnasso, op. cit., pp. 325-328.}

11 Cuadernos El Público (1989), “José Bergamín, un teatro peregrino”, Madrid, 39 (abril 1989), p. 71.

12 Carlos Gurméndez, "Conversación con José Bergamín: Un teatro de pasión o la pasión del teatro", El País, (26 enero 1980), Suplemento de Artes, p. 5.

13 Ma Teresa Santa María Fernández (1999), "Repertorio teatral de José Bergamín", en El exilio teatral republicano de 1939, ed. Manuel Aznar Soler, Sant Cugat del Vallès, Associació d'Idees / GEXEL (Sinaia, 4), 1999, pp. 375-376.

14 José Esteban, "Bergamín de viva voz”, en José Bergamin: La escritura, simbolo de exilio y peregrinación, Revista Anthropos: Huellas del conocimiento, 172 (mayo-junio 1997), pp. 25-26. 


\section{LA SANGRE DE ANTÍGONA}

Resulta curioso que esta obra, concebida como ópera junto con la música del compositor también exiliado, Salvador Bacarisse, haya sido estrenada en 2013 por la Compañía Nacional de Teatro de México dentro del XVI Festival Internacional Cervantino de Teatro de Guanajuato y representada por esta misma compañía en el Teatro María Guerrero de Madrid del 11 al 14 septiembre de 2014. Nos encontramos así con una obra que se ha empezado a representar mucho más tarde de la fecha en que fue compuesta, ya que a la producción del CNT tenemos que sumar las representaciones que se produjeron en escenarios de Mendoza (Argentina), Verona (Italia) y Valencia (España), por compañías no profesionales.

Este "misterio en tres actos" alterna, como las tragedias griegas, las partes recitadas, en prosa, con las cantadas, en verso. Ese acompańamiento musical, que supone un pilar en su génesis de la mano de Bacarisse, no ha podido lucirse aún en su presentación como ópera en ninguna de las cuatro representaciones antes mencionadas. Pero la presencia de la música ha sido parte importante en todas ellas. Así, sabemos que la que se dio cita en el Festival de Verona en 2003, a cargo de veinticuatro estudiantes del Laboratorio Teatral Universitario, y contó con "un coro y una voz soprano, y de cinco músicos excelentes de flauta, saxo, guitarra, acordeón y percusiones; uno de ellos, Carlo Ceriani, se encargó de la adaptación de las canciones y acompañamientos musicales y compuso un tema original para esta puesta en escena"15; e igual relevancia de la música, en esa ocasión vinculada con un estilo de pasodoble y de Semana Santa, encontramos en la estrenada bajo la dirección de Ignacio García en Guanajuato, México D.F. y Madrid ${ }^{16}$.

En otros lugares hemos podido estudiar esta obra con más detenimiento, así que nos limitaremos a reseñar aquí aquellos elementos que denotan esa influencia francesa que su génesis y escritura durante los años

15 Paola Ambrosi, "El fantasma de la Antígona bergaminiana en la puesta en escena de Guillermo Heras", en Análisis de espectáculos teatrales (2000-2006), ed. José Romera Castillo, Madrid, Visor Libros, 2007, pp. 221-235.

16 Ma Teresa Santa María Fernández, "La re-vuelta de José Bergamín. Crónica del estreno en el Teatro María Guerrero de Madrid de La sangre de Antígona", Laberintos, 16 (2014), pp. 502-504. http://bv.gva.es/documentos/lab16.pdf 
cincuenta en París nos delata. Como bien recoge Christiane Heine, la colaboración entre Bacarisse y Bergamín para realizar este proyecto se fragua nada más llegar este último desde Montevideo a París en 1954 y su intención era estrenarla en Nápoles o en Montevideo en $1956^{17}$. Nos interesa también resaltar que Roberto Rossellini había encargado la obra al compositor al conocerlo unos meses antes y estuvo de acuerdo en que Bergamín, a sugerencia de Bacarisse, se encargara del libreto ${ }^{18}$. Pero lo que resulta más revelador es que la idea era realizar una obra al estilo de Juana de Arco en la hoguera del escritor francés Paul Claudel.

Roberto Rosellini acababa de adaptar en 1954 este oratorio para el cine, con su mujer, Ingrid Bergman, en el papel de Juana de Arco y con el título de Giovanna d'Arco al rogo. Pero la pieza, basada en un poema de Claudel y con música de Arthur Honegger, se había estrenado años antes, en 1938 con la bailarina y actriz Ida Rubistein como protagonista, y en 1941, en la Francia no ocupada, con Jacqueline Morane en el papel principal. La obra, en su gira americana, se estrenó en el Auditorio del SODRE (Servicio Oficial de Difusión, Radiotelevisión y Espectáculos) de Montevideo el 30 de noviembre de 1946 y se repuso en $1947^{19}$. Aunque Bergamín no llegó a Uruguay hasta finales de ese ańo, bien pudo saber de dichas representaciones en Francia y en Montevideo o de las que se produjeron en el Teatro Colón de Buenos Aires en 1948 y que dieron lugar a la traducción del texto al español ${ }^{20}$.

Las semejanzas formales y conceptuales entre la obra de Claudel y la Antígona de Bergamín son varias. Formalmente, ambas obras se asemejan por esa combinación entre partes cantadas y recitadas, que permiten que ambos elementos -música y actuación- sean representadas de manera separada; por la presencia de niños o niño -en el caso de Bergamín-, en

17 Christiane Heine, op. cit., pp. 43-75.

18 Yves Roullière, "L'Antigone de José Bergamín” en Les Antigones contemporaines (de 1945 à nos jours), eds. Rose Duroux et Stéphanie Urdician, Clermont-Ferrand, Presses Universitaires Blaise Pascal, 2010, p. 219.

19 De esa reposición de 1947 da fe el artículo de Jacques Després, "Juana de Arco en la hoguera”, Anales del Ateneo. Revista Uruguaya de Cultura, 2 (junio 1947), pp. 196198.

20 Paul Claudel y Arthur Honnegger, Juana de Arco en la hoguera. Oratorio dramático, trad., prol. y notas de Ángel J. Battistessa, Buenos Aires, Secretaría de Cultura de la Municipalidad de Buenos Aires, 1948. 
la escena; la importancia del coro, al estilo de la tragedia clásica o la aparición del Corifeo o de un "Récitant" en algunos momentos de la obra. También dentro de ambas piezas el presente y el pasado se van entremezclando en la trama para revelarnos las razones de las condenas de ambas. Además, ese concepto de "oratorio" o "misterio" les confiere también un ritmo pausado, litúrgico, que les adentra en una dimensión religiosa que resulta transcendental en ambas obras.

En segundo lugar, tenemos que destacar el contenido religioso de ambas piezas. Bergamín conocía perfectamente la labor del escritor francés pues, por ejemplo, publica en la revista Cruz y Raya, que él dirigía varios textos de Claudel, como el ensayo titulado "Sobre la presencia de Dios"21; una reseńa de Leopoldo Panero - precedida por un pequeńo fragmento de "Sur Víctor Hugo"- sobre su drama lírico "El libro de Cristóbal Colón" 22 o algún otro fragmento suelto ${ }^{23}$. También el propio Bergamín lo cita al hablar sobre poesía católica en el homenaje que la revista dedicó a Lope en uno de sus números ${ }^{24}$ o se reseña su inclusión dentro de los firmantes del "Manifiesto de los católicos" que la misma Cruz y Raya reproduce ${ }^{25}$. Pero, sobre todo, destaca su texto "La superación de la tragedia", publicado en Índice, donde nuestro autor analiza las interpretaciones que la crítica de su época hizo sobre las tragedias, en especial las realizadas por autores franceses como Paul Claudel y sus traducciones de Esquilo ${ }^{26}$.

21 Paul Claudel, "Sobre la presencia de Dios", Cruz y Raya, 11 (febrero 1934), pp. 8-47. El texto, según carta de Bergamín a Manuel Falla, del 20 de octubre de 1933, había salido en la revista francesa, también de inspiración católica, Esprit, y "está haciéndonos la traducción Jorge Guillén, para conservarle todo el valor poético, tan vigoroso, de la prosa claudeliana" (El epistolario (1924-1935): José Bergamin / Manuel de Falla, Edición de Nigel Dennis, Valencia, Pre-textos, 1995, p. 104). Para más información, véase también Milagros González Izquierdo, "Cruz y Raya: Manuel de Falla y Miguel de Unamuno", Revista de Filología de la Universidad de La Laguna, 16 (1998), pp. 83-102.

22 Cruz y Raya, 28 (julio 1935), pp. 86-93.

23 Cruz y Raya, 38 (mayo 1936), p. 120.

24 José Bergamín, "Lope, siguiendo el dictamen del aire que lo dibuja”, Cruz y Raya, 23-24 (febrero 1935), p. 50.

25 José Bergamín, "Paz con paz, guerra con guerra”, Cruzy Raya, 33 (diciembre 1935), pp. 105-112. También lo cita Manuel Abril tras reproducir un texto suyo (pp. 140-141) en "Las sílabas de Dios o la poesía pura", Cruz y Raya, 7 (octubre 1933), pp. 133-153.

26 José Bergamín, "Márgenes”, Índice, 3 (1921), pp. XII-XVI. 
Tampoco descarta María Milagros González Izquierdo la posibilidad de que Bergamín lo hubiera conocido en persona, pues Claudel "fue huésped de la Residencia en julio de $1925^{\prime 27}$, y apunta también que, tras la guerra y estando Bergamín en París camino de México, recibió "noticias del asalto a su casa de la calle Claudio Coello en Madrid. Su biblioteca fue destruida y se perdió gran parte de la correspondencia que mantuvo con Max Jacob, Machado, Unamuno, Paul Claudel, Juan Ramón"28. Sin embargo, queda documentado que la buena relación entre ambos escritores se resintió a causa de la crítica que José Bergamín, en su artículo "Al servicio de Alemania (Paul Claudel y Cía.)" 29 , vertió a la postura del escritor francés. En efecto, Claudel había defendido la legitimidad del bando nacional porque se enfrentó a la persecución religiosa en la España Republicana a través de su poema "Aux martyrs espagnols", publicado en la revista $S e p t^{30}$. Y, desde luego, su posición no gustó nada al escritor exiliado pues, como señala Sanz Barajas, "Bergamín está en manifiesto desacuerdo con cualquier programa político que utilice al catolicismo como bandería" 31 .

Por otro lado, destaca como tercera similitud elegir una trama protagonizada por una mujer que debe elegir entre su deber moral o la condena a muerte por seguir siendo fiel a las ideas que defiende. $\mathrm{Y}$ en este sentido nuestro dramaturgo no hace otra cosa que seguir la estela de otros autores franceses contemporáneos suyos que integraron el mito de Antígona dentro de su repertorio. Nos referimos a los casos de Anouilh, Cocteau y Gide.

La versión de Jean Cocteau se estrenó el 20 de diciembre de 1922 en L’Atelier de París, con decorados de Picasso, música de Honegger y trajes

27 María Milagros González Izquierdo, Tradición y renovación poética en la obra de José Bergamin, La Laguna, Universidad de La Laguna, tesis doctoral, p. 185, nota 501.

28 Ibidem, p. 119.

29 José Bergamín, “Al servicio de Alemania (Paul Claudel y Cia.)”, Hora de España, 14 (febrero 1938), pp. 69-72.

30 Para dicha polémica, véase Gonzalo Redondo, Historia de la Iglesia en España, 19311939, II, Madrid, RIALP, 1993, pp. 279-282. Una edición reciente del poema de Claudel puede verse en $A$ los mártires españoles, trad., introd. y notas de Tomás Salas, Madrid, Encuentro, 2009.

31 Jorge Sanz Barajas, José Bergamin: la paradoja en revolución (1921-1943), Tesis doctoral presentada el 22-12-9, Universidad del País Vasco (Departamento de Derecho Constitucional e Historia de las Ideas Políticas), p. 12. 
de Chanel. Se trata de una adaptación de la tragedia de Sófocles, pero esquematizándola aún más y con una lengua escueta y depurada. Causaron un enorme impacto tanto esa representación como su reestreno en 1927, en el que "Cinco monumentales cabezas representaban al Coro, máscaras de latón blanco cubrían los rostros. Los trajes eran maillots negros cubriendo todo el cuerpo. Cocteau quería que el conjunto evocase un carnaval sórdido y real, una familia de insectos" 32 . Si Cocteau se atrevió a otorgar una presentación escénica a la tragedia fuera de sus cánones habituales, será Gide, en 1930, con su OEdipe, quien se atreva a reinterpretar y dar su propia visión del mito, sin seguir tan al pie de la letra los modelos griegos. De esta forma, la obra estará acorde con la peculiar manera de entender la vida de su autor, tal y como este la había reflejado en otras obras suyas, la aversion hacia la familia. Por tanto, "André Gide’s Antigone is one of those young women of cloistered radiance [...].Antigone wishes to become a nun, to return to those who have schooled her towards God. Gide's Polynice, on the contrary, is a budding immoralist" 33 .

Por último, la tercera versión del mito de Antígona de un escritor francés, contemporáneo a Bergamín, es la de Jean Anouilh, de 1942. La acción se desarrolla en Tebas, pero durante la II Guerra Mundial, por lo que encontramos diversas alusiones a elementos característicos del siglo XX: los filmes, los coches, cigarros, etc. Y no solo se reviste la tragedia superficialmente de formas actuales, sino que también plantea problemas de aquellos tiempos: "negativa a la comunicación, aislamiento, resentimiento hacia los que no la comprenden, el mundo hostil de los mayores, su aferrarse a una infancia absurdamente eterna" ${ }^{34}$. Pese a que todos los personaje, incluido Creón, realizan lo posible para salvarla, la Antígona de Anouilh se aferra a la muerte, más por una actitud irrazonable y obstinadamente nihilista que por un ideal que quiera llevar hasta sus últimas consecuencias. Este último aspecto, el intento de todos los personajes para que no muera Antígona, aparece también en la pieza de Bergamín, aunque en la suya prevalezca esa revisión cristiana del mito que se inició ya en el siglo XVI y que llevaba a comparar su figura con la de Juana de Arco o Margarita Moro.

32 Carmen Bosch Juan, Antígona en la literatura moderna (Resumen de la Tesis), Barcelona, Universidad de Barcelona, 1979, p. 14.

33 George Steiner, Antigones, Oxford, Clarendon Press, 1984, p. 163.

34 Carmen Bosch Juan, op.cit., p. 14. 


\section{LA CAMA, TUMBA DEL SUEÑO}

Además de la edición que apareció junto con La sangre de Antígona en Primer Acto, la obra ha sido publicada en $A r t$ Teatra ${ }^{35}$ y la compañía Theatre Lucifers la estrenó en junio de 1993, con la participación de su nieta, y actriz, Beatriz Bergamín. El texto de Bergamín y el de Baudelaire fueron de la mano en la Sala Cuarta Pared de Madrid, pues se representó la pieza bergaminiana seguida de La habitación doble. Precisamente, este poema en prosa que se incluye en El Spleen de París será el que lea el personaje de Él, enmascarado en su aparición al inicio de la Escena Segunda (LCT ${ }^{36}$ : 439 y ss.) y el que inspire el título y texto de la obra, tal y como aparece debidamente reseńado en Primer Acto.

"El doble aposento" o "La habitación doble" 37 corresponde a un texto de carácter autobiográfico, donde el poeta francés se enfrenta con sus fantasmas: la Realidad, el Tiempo y la Vida. Además de la huella de Baudelaire, esta pieza evoca también las representaciones y metáforas sobre la vida y la muerte que nos ofrecen dos autores barrocos, Quevedo y Calderón. Del primero, publicó Bergamín una selección de La cuna y la sepultura en Cruz y Raya en 1936, y citó una reflexión suya en numerosas ocasiones, como en El pensamiento perdido ${ }^{38}$; o en el capítulo de Los ángeles exterminados, emitido por la televisión francesa en 1975 y que se transmitió dentro de "La noche temática" de TVE2 el 30 de junio de 1996: "No es la muerte una calavera con guadaña, sino los muertos; estos huesos son el dibujo sobre el que se labra el cuerpo del hombre. La muerte

35 José Bergamín, "La cama, tumba del sueño o El dormitorio", Art Teatral. Cuaderno de minipiezas ilustradas, Valencia, IV, 4 (1992), pp. 7-15.

36 Aludimos dentro del cuerpo de texto a La cama, tumba del sueño como LCT y, tras dos puntos, indicaremos el número de página -o en su defecto, el número de los versos precedido por "vv."-, según la edición que aparece en Ma Teresa Santa María Fernández, El teatro en el exilio de José Bergamin. Tesis doctoral, Bellaterra, UAB, (12 de julio de 2001), pp. 912-1031. http://www.tdx.cat/bitstream/handle/10803/4880/ mtsmf1de1.pdf?sequence $=1$. Otras piezas que citaremos en el artículo son: Los tejados de Madrid (LTM), Melusina y el espejo (MYE) y Tanto tienes cuanto esperas (TT).

37 Charles Baudelaire, Obras poéticas. Madrid, Aguilar, 1963, pp. 375-376.

38 José Bergamín, El pensamiento perdido, Madrid, Adra, 1976, p. 118. 
no la conocéis y sois vosotros mismos vuestra muerte..."39.

Esta idea de la muerte como compañía inseparable del hombre se complementa con la imagen barroca de la tumba vinculada a la cuna y, por tanto, al nacimiento de cada uno de nosotros y que podemos encontrar, por ejemplo, en algunas obras de Calderón, que Bergamín conocía muy bien:

\author{
FERNANDO. [...] \\ Pisando la tierra dura \\ de continuo el hombre está, \\ y cada paso que da \\ es sobre su sepultura ${ }^{40}$.
}

Pero, sobre todo, Bergamín evoca en La cama, tumba del sueño al Calderón de La vida es sueño, donde también su protagonista asocia, en una de sus intervenciones, los dos lugares que acompañan el sueño del hombre, desde los primeros hasta sus últimos días:
SEGISMUNDO. [...]
Tan poco del mundo sé, que cuna y sepulcro fue esta torre para mí: y aunque desde que nací (si esto es nacer) sólo advierto este rústico desierto, donde miserable vivo, siendo un esqueleto vivo, siendo un animado muerto ${ }^{41}$.

Por otro lado, a lo largo de la obra los protagonistas se interrogarán, siguiendo no solo a Baudelaire y Calderón, sino a otros autores como Herá-

39 Francisco de Quevedo, La visita de los chistes, en Obras de Quevedo, I, Madrid, Atlas (Biblioteca de Autores Españoles, 23), 1946, p. 335.

40 Pedro Calderón de la Barca, El principe constante. La vida es sueño. El alcalde de Zalamea. Los encantos de la culpa, estudio preliminar de José Bergamín, Barcelona, Océano, 1999, p. 93.

41 Ibidem, p. 116. 
clito, Novalis o Augusto Ferrán, sobre la realidad o ensoñación de cuanto están viviendo. Por tanto, esa noción del mundo como sueño se completa con todas las posibilidades que la metáfora o imagen del "sueño" puede aportar. Así, el sueño puede ser tanto la muerte como la felicidad (LCT: 436); un espacio como esa "alcoba que parece un sueño" sobre la que gira el título y toda la obra (LCT: 439); el Espectro o Ídolo que tanto conmociona al poeta francés y a nuestro dramaturgo (LCT: 440); o bien indicar la confusión entre realidad y ficción (LCT: 442) -en la vida y en el teatro-, ya que en ocasiones permanecemos en ellas, "como dentro de un sueño" (LCT: 443). Bergamín no nos desvela qué acepción resulta la adecuada, si se trata de un sueño real o de una realidad sońada o teatralizada, ni tampoco qué "tú" se esconde tras la pregunta que ELLA realiza al principio y al final de la obra, pero de cuyo sortilegio tampoco escapamos nosotros, los lectores-espectadores: “Quién eres tú?” y “¿Y tú, no eres tú?” (LCT: 430 y 445).

Tres particularidades encontramos, además, en esta pieza dramática. En primer lugar, está íntegramente escrita en prosa, al igual que las obras que constituyen su teatro de Vanguardia ${ }^{42}$ o que La hija de Dios. En segundo lugar, no se especifica el "subgénero" de la misma, como sí ocurre en casi todas sus obras del exilio. Y, por último, la ambientación de los hechos resulta manifiestamente irreal e indeterminada, mientras que Bergamín solía especificar y ofrecer más detalles sobre la época y lugares en que transcurrían sus obras escritas en el exilio. Únicamente, en Melusina y el espejo se aprecia idéntica imprecisión espacio-temporal: "La acción en la ciudad de Melusa, capital de Melusia, y sus alrededores. Época melusiana" (MYE: 171). En el caso de La cama, tumba del sueño, la acotación inicial nos sitúa en un espacio literario e irreal, idéntico al descrito por Baudelaire en su poema: "Un aposento que se asemeja a una fantasía, un aposento verdaderamente espiritual, cuya estancada atmósfera está ligeramente matizada de azul y de rosa" ${ }^{\prime 3}$.

De esta forma, la idea general de la obra se corresponde con el carácter irreal del lugar donde transcurre y sobre el que incidirán algunas de las acotaciones e intervenciones de los personajes. Así, se nos describe dicho

42 José Bergamín, Teatro de Vanguardia (Una noción impertinente), ed. Paola Ambrosi y pról. de Nigel Dennis, Valencia, Pre-Textos, 2004.

43 Charles Baudelaire, op. cit., p. 375. 
dormitorio como "lo más parecido al que fuera expuesto en el escaparate de una mueblería de lujo" (LCT: 429), o se nos indica que los protagonistas tocan sus muebles para comprobar si son reales (LCT: 433). En otro momento se hace referencia a sus puertas y a ese ventanal infranqueable (LCT: 434-435) que, a pesar de estar cerrados como "con cien llaves", se abren sin problemas al final de la obra (LCT: 445), o son atravesados "sin abrirlas" por los fantasmas (LCT: 439). Por otro lado, esta sensación de irrealidad viene también intensificada en los diálogos, donde se plantea la duda de si se trata de un espacio teatral o de un escaparate (LCT: 431), o quizás de "una alcoba que parece un sueño", como la de Baudelaire (LCT: 439).

También esa teatralización y especulación sobre la realidad y lo soñado constituye, como indicábamos, el tema fundamental de las tres escenas y la escena final en que se divide la obra. En la primera de ellas la irrupción de ÉL y ELLA en el escenario, procedentes del proscenio, ya nos obliga a decidir si son actores en realidad o público como nosotros, si tienen existencia real o bien asumen un anonimato que les permite representar a cualquier hombre o mujer. Por otro lado, los diálogos que se suceden entre ellos cuestionarán otros hechos: si se conocían o habían visto antes, de dónde han venido, qué hacen en esa alcoba y quiénes son realmente. De entre todas esas cuestiones destacan cuatro: la impresión de haber soñado o vivido esa situación con anterioridad (LCT: 431); la constatación de que no pueden escapar de esas cuatro paredes cuya realidad física resulta innegable (LCT: 434); la sensación de que el tiempo y el espacio se han parado en ese instante (LCT: 434 y 440) y los interrogantes que surgen entre dos personas reunidas al azar y que no reciben respuesta.

Las dudas no desaparecen, sino que se incrementan con la aparición de los dos fantasmas enmascarados en la segunda escena. Aunque golpean físicamente las puertas (LCT: 438), las pueden atravesar sin problemas, por lo que Bergamín no duda en aludir a ellos como "fantasmas" (LCT: 438 y 439). Además, son descritos de forma "convencional", por los "trajes románticos" que visten, y "teatral”, por sus máscaras y porque, al contrario que ÉL y ELLA, no surgen del público, sino de dentro del escenario. Se suceden así siete cuadros diferentes donde se duplican no solo los personajes, sino los diálogos entre los mismos. El primero y último cierran el círculo y sirven como contrapunto, pues en uno aparecen ÉL ENMASCARADO y ELLA ENMASCARADA elucubrando sobre 
la realidad que leen -fragmentos del poema de Baudelaire- y ven (LCT: 439-441); mientras que en el que cierra esta escena segunda los personajes de ÉL y ELLA dudan sobre la conveniencia de salir o permanecer en el aposento-tumba (LCT; 447). En medio se suceden otros cuatro diálogos cruzados entre ÉL y ELLA ENMASCARADA, y ELLA y ÉL ENMASCARADO (LCT: 441-443); y un quinto donde los dos personajes enmascarados repiten como un eco las intervenciones de los otros dos personajes (LCT: 443-444).

La inquietud se cierne, de esta forma, sobre los personajes no enmascarados, cuyas sombras o dudas espirituales se hacen físicas, al hacerse "el oscuro". Oscuridad que permanece en la breve escena tercera, compuesta por un nuevo diálogo cruzado entre los personajes que se repite por dos veces. En él los personajes enmascarados guían hacia la luz a su pareja "real" de sexo opuesto. Y la luz se hace, por fin, en la escena final, donde ELLA y ÉL serán los que se quiten los antifaces para descubrirse de nuevo: “-ÉL. Ah!, ¿̨no eres tú? -ELLA. ¿Y tú, no eres tú?” (LCT: 445). Preguntas decepcionadas, pero que recuerdan las que inician la obra: “- ELLA. ¿Quién eres tú? -ÉL ¿Y tú?” (LCT: 430).

Esta estructura cíclica y repetitiva nos recuerda a ese tipo de cuentos o historias que nunca acaban, sino que vuelven a empezar, tal y como encontramos en La niña guerrillera o en Melusina y el espejo. También coincide con ambas obras en el uso de las repeticiones o la agrupación de personajes, aunque en este caso sea dual y no triple, como en las piezas referidas. Por otro lado, ese contraste entre la luz y la oscuridad supone una cuestión muy bergaminiana. Así lo recoge Bergamín en uno de sus aforismos: "POETA: no le tengas miedo a la oscuridad. Mientras más oscuro es el poeta, más clara es su poesía" ${ }^{4}$.

Por otro lado, esta pieza se aleja de otras obras en el exilio pues no estamos ante un mito literario de honda tradición literaria ni tampoco ante una representación donde la música, la poesía o el coro tomen parte activa de su puesta en escena. De ahí que algunos estudiosos señalen esta pieza como un regreso a su primer teatro:

La redacción de Tres escenas en ángulo recto o de Enemigo que huye en

44 José Bergamín, El cohete y la estrella. La cabeza a pájaros, Madrid, Cátedra, 1981, p. 114. 
los años veinte y las de Melusina y el espejo y Medea, la encantadora en los cincuenta avalaría la idea de un abandono de la experimentación si no hubiera escrito en fecha más reciente -hacia 1956- La cama, tumba del sueño o El dormitorio ${ }^{45}$.

De todas maneras, la "rareza" manifiesta de la pieza que nos ocupa queda compensada por otros rasgos del más puro estilo bergaminiano que aparecen en La cama, tumba del sueño. Nos referimos al aire rápido y aforístico de los diálogos, su afición por duplicar escenas o personajes $-\mathrm{O}$ incluso intervenciones dentro de una obra, así como el aire de duda manifiesta ante la realidad exterior que denotan todas las páginas de esta pieza. Todas ellas también nos remiten al teatro de vanguardia o de juventud de Bergamín, en el que destacan

los diálogos repletos de aforismos, de referencias filosóficas o de construcciones verbales de una inaudita imaginación, sus vinculaciones con movimientos artísticos de las vanguardias de los veinte y treinta tales como la Bauhaus o el Constructivismo; la gran carga de fina ironía, de homenaje al teatro popular de otros tiempos, hacen de su teatro intelectual un placer que va más allá de la ramplonería con que el género de literatura dramática se ha tratado en muchos momentos de nuestra historia ${ }^{46}$.

Estaríamos, por tanto, ante una invitación a pensar o a reflexionar a partir de ese interrogante que, a modo de obra dramática, nos lanza Bergamín, como en otras ocasiones lo ha hecho bajo la forma de un aforismo o un poema determinado. En este caso, además, la inconsistencia de nuestra realidad, el enmascaramiento de los rostros de la persona se entremezclan con la falsedad y la imposibilidad de conocer y aprehender cuanto surge ante nuestros ojos. Surge, así, la relación de la obra con el mito de la caverna de Platón y también el rostro como máscara de las personas, que toma y cita en repetidas ocasiones de Nietzsche.

45 Jerónimo López Mozo, "Bergamín y la cuadratura del círculo (seguido de un paseo por Melusina y el espejo)”, Cuadernos El Público, Madrid, 39 (abril 1989), p. 15.

46 Guillermo Heras, "Divagaciones sobre el primer teatro de José Bergamín”, en José Bergamin: La escritura, simbolo de exilio y peregrinación, Revista Anthropos: Huellas del conocimiento, 172 (mayo-junio 1997), pp. 79-80. 
Pero, además, el miedo e imposibilidad de "salir al exterior", de conocer otras realidades, nos conducen a la situación política de España en ese momento. Recordemos que estamos en 1956, antes de la primera vuelta de Bergamín a España. En esos años ya había reflejado en La sangre de Antígona sobre el diferente e injusto tratamiento que reciben los vencedores y vencidos en una guerra civil. En La cama, por su parte, verterá su opinión sobre la actual situación de los españoles, quienes, incapaces de salir por sí mismos del ostracismo en que los ha colocado la dictadura de Franco (LCT: 434), se inventan diversas puertas de escape para su existencia. Así, aunque les parece una tumba la alcoba en que se hallan, prefieren idealizarla como dormitorio nupcial o elemento escénico de esa comedia que reconocen estar representando (LCT: 431). Sin embargo, ese sueño de felicidad eterna al que creen estar invitados se rompe con la llegada de la pareja enmascarada, verdaderos fantasmas que despiertan la conciencia de los dos protagonistas, desesperándolos con las dudas e inquietudes sobre ese nirvana en que creían estar sumidos. Y no podemos olvidar, por último, las ocasiones en que Bergamín se define a sí mismo como un "fantasma", tal irreal o real como el que aparece en esta pieza y a la que su vida como exiliado le había abocado.

\section{LOS TEJADOS DE MADRID}

El interés hacia Lope de Vega por parte de Bergamín resulta una constante a lo largo de su vida y de su obra ${ }^{47} y$, por tanto, no resulta extrańo que con motivo del cuarto centenario del nacimiento del gran dramaturgo barroco, se decidiera a publicar su versión de La Gatomaquia, según señala la nota de redacción que precede a la edición en 1961 de la obra:

La proximidad del centenario de Lope de Vega hace de este autor un tema del que habrá que ocuparse de un modo preferente. Sea la publicación de la teatralización, hasta ahora inédita, que ha hecho José Bergamín de La Gatomaquia, un primer testimonio de nuestro inte-

47 Ma Teresa Santa María Fernández, "Lope y Bergamín por los tejados de Madrid", en Escritores, Editoriales y Revistas del exilio republicano español de 1939, ed. Manuel Aznar Soler, Sevilla, Renacimiento, 2006, pp. 1121-1127. 
rés por el centenario y la coyuntura que nos ofrece para reconsiderar los valores de nuestro gran dramaturgo. La mediación personalísima del escritor José Bergamín nos parece de gran interés ${ }^{48}$ (LTM, p. 326, nota 1$)$.

En efecto, la celebración del nacimiento de Lope, que acaeció en 1562, suponía una buena excusa para publicar en Madrid una obra que ya llevaba varios años en la mente de Bergamín. Sabemos, por una carta que envió a su amigo Justino de Azcárate desde Montevideo que, en 1953, debía tener prácticamente terminada "la adaptación escénica de la estupenda Gatomaquia, de Lope. En tres actos, titulándola: El amor anduvo a gatas. ¿Qué te parece que la mandase anónima a Madrid? Sería gracioso estrenarla allá”’99. Si bien nuestro autor no consiguió su propósito de estrenarla ni en nuestro país ni fuera, ya que únicamente se han representado algunas escenas en el programa Masques et bergamasques que emitió la Televisión Francesa el 21 de abril de 1970, al menos pudo ver cómo se publicaba por primera vez en España una de sus obras teatrales escritas en el destierro. La razón obedece a que en esos momentos se hallaba en Madrid, ciudad donde residió desde 1958 a 1963, para huir de nuevo al exilio. Sin embargo, su inclusión en la lista de las "Acotaciones a Medea" de 1954, dentro de "los proyectos a medio escribir" 50 , nos permite ańadirla dentro de las obras que Bergamín terminaría de escribir, con toda seguridad, en su primer exilio en París.

En su versión "personalísima” del texto de Lope, Bergamín recoge del autor barroco las silvas que configuran $L a$ Gatomaquia ${ }^{51}$ y en todos estos versos que conforman la pieza teatral se nos revela el Bergamín editor, que reproduce al pie de la letra su modelo y que, más que copiar, recuerda esas estrofas tan queridas y tantas veces recordadas desde el exilio. Así, de mil ochocientos veintiún versos que conforman Los tejados, casi una tercera parte -quinientos treinta y cinco versos- obedecen a la creación e inge-

48 José Bergamín, Los tejados de Madrid o El amor anduvo a gatas, Primer Acto, 21 (abril 1961), pp. 22-39.

49 Gonzalo Penalva, op. cit., p. 177.

50 Rogelio Martínez y Alicia Cagnasso, op. cit., p. 328.

51 Lope de Vega, La Gatomaquia, ed. Celina Sabor de Cortázar, Madrid, Castalia, 1982. 
nio de Bergamín, mientras que el resto pertenece a Lope de Vega. Pero, además, seguimos encontrando en Los tejados de Madrid otras referencias a la obra del Fénix, como canciones o poemas que recoge de algunas de sus comedias (LTM, vv. 381-417, 418-446, 618-631, 969-1064, 15581571, 1572-1585, 1686-1701, 1707, 1730-1739), de La Dorotea (LTM, vv. 757-828 y 1648-1685) o de otras composiciones (LTM, vv. 896-901 y 907-917).

Otro aspecto que remite a La Gatomaquia sería la referencia expresa, en la acotación inicial, a que todos los personajes visten y llevan "en vez de espadas, cucharas de palo o hierro y cucharones, etc., conforme a su descripción en LA GATOMAQUIA" (LTM, 327). De esta manera, aunque Bergamín no incluya en las acotaciones de Los tejados de Madrid la descripción física o vestimenta de los personajes, conocemos cómo quería que aparecieran en escena. Por otro lado, esta primera acotación le descarga de incluir, precisamente, esos pasajes del poema lopesco en que se nos explica cómo van vestidos Marramaquiz (Silva I, vv. 104-123), Micifuz (Silva III, vv. 19-37) o Zapaquilda (Silva V, vv. 209-236).

En tercer lugar, la presencia de ese narrador -convertido al final del acto I también en el personaje del alguacil que apresa a los dos rivales amorosos- obedece a un detalle ya presente en La Gatomaquia y que Bergamín amplifica, dándole mayor relevancia. De esta forma, personaliza a Taratántara, quien constituía una mera onomatopeya para indicar el ruido del tambor en su modelo (Silva I, v. 12). Pero al margen de las funciones de prólogo, narrador o personaje, esta figura simboliza ese espíritu belicoso o épico que, al final de la obra, pierde protagonismo en aras de otorgarle un aire más festivo y amoroso, tal como indica la propia Zapaquilda:

(TARATÁNTARA se dispone a volver a tocar su estrepitoso tambor, adelantándose al proscenio, cuando ZAPAQUILDA, tomándole de un brazo, se lo impide, y adelantándose ella, dirá:)

ZAPA. ¡Cese el tambor guerrero,

Taratántara fiero!

¡Déjame a mí decir lo que yo quiero!

Que ahora será de boda y alegría

la de gatos feliz algarabía. (Al público). (LTM, vv. 1802-1806) 
Por otra parte, el rechazo de Zapaquilda a ese espíritu épico que encierra la obra destaca en otros aspectos de su adaptación del poema lopesco, pues no conviene olvidar que ella -Zapaquilda o Teresa "Vericundia"- es la autora de la versión para el teatro de la figuración de Tomé de Burguillos. Así, si La Gatomaquia supone la peculiar mirada burlesca de Lope sobre la epopeya clásica o el Orlando furioso de Ariosto, nos encontramos con que en Los tejados de Madrid se eliminan algunas de esas referencias épicas, como algunas alusiones a los poemas homéricos, La Ilíada y La Odisea, o a La Eneida de Virgilio, que sí aparecían en La Gatomaquia, (Silva II, vv. 184-189 y 192-195 o en Silva VII, vv. 97-98, 132-141).

Más significativas resultan las ausencias de alusiones al Orlando furioso, pues en la parodia lopesca ocupaban mayor espacio e importancia de los que les asigna nuestro autor exiliado en Los tejados de Madrid. Por ejemplo, en los versos 76-77 cambia los dos originarios de La Gatomaquia: "a visitar a Angélica la bella, / la recatada ninfa, la doncella" (Silva I, vv. 131-132) por "Zapaquilda, tan bella / cual recatada ninfa, cual doncella”; o llega a incluso a eliminar el tema de la locura celosa que ocupa lugar destacado y central en el poema de Lope (Silva IV, vv. 326-393). Sin embargo, mantiene algunas citas o alusiones a personajes de la obra de Ariosto (Silva II, vv. 237-240 y Silva VI, vv. 2-6 y 13-14).

Además, en su introducción a La Gatomaquia, Celina Sabor de Cortázar destaca como rasgo representativo de la épica la presencia de digresiones y símiles, que serán parodiados por Lope en su obra, como:

los celos (II, 3-12); el desprecio de los bienes mundanos (III, 23942); la debilidad de la cabeza de los gatos (III, 23-26); el engaño a los ojos (II, 333-338); los poetas y la poesía (III, 69-79; V, 22-38 y 39-71); la abundancia de calvos en España (V, 52-56); el retrato de la muerte (IV, 205-22); la ocasión y la tardanza peligrosa (VI, 56-63), etc. A veces la digresión es compleja, pues consta de dos o más digresiones encadenadas. Así, en la Silva VII (vv. 77-144), se desarrollan sucesivamente, sin solución de continuidad: una consideración sobre los pigmeos y sus cabalgaduras, otra sobre la batalla de los pigmeos y las grullas, y otra sobre las invenciones mentirosas de los poetas ${ }^{52}$.

52 Celina Sabor de Cortázar, "Introducción” en Lope de Vega, op. cit., pp. 29-30. 
Sin embargo, de los diez ejemplos citados, solo uno -el del retrato de la Muerte- aparece en Los tejados de Madrid (LTM: 346, vv. 640-658). Y algo similar ocurre con otros extensos símiles que Lope incluye en su parodia y que son obviados por Bergamín en su versión.

Otro aspecto que enlaza la versión de Bergamín con la de Lope "al pie del espíritu" lo constituyen la inclusión de poema y canciones dentro de Los tejados de Madrid. No solo la presencia de los músicos en La Gatomaquia autoriza plenamente la conveniencia de incluir esas partes cantadas en la adaptación teatral, sino que también, en otro momento del poema lopesco, se alude a un personaje -concretamente Zapaquilda- cantando un soneto, con lo que se justifica la aparición de poesías alternando con las silvas: "Ya que lavada estuvo, / y con las manos que lamidas tuvo, / de su ropa de martas aliñada, / cantó un soneto en voz medio formada / en la arteria bocal, con tanta gracia / como pudiera el músico de Tracia (Silva I, vv. 64-69).

Por último, conviene destacar ese juego de paralelismos que existe entre La Dorotea y La Gatomaquia, que también está presente en Los tejados de Madrid. Sabemos que ese amor durante su juventud por Elena Osorio marcó toda la vida y obra de Lope de Vega, quien fue desplazado por don Francisco Perrenot de Granvela, indiano ilustre y adinerado. Este episodio juvenil "se va a transfigurar en poesía a lo largo de toda su vida, desde Belardo el furioso (hacia 1588) hasta La Gatomaquia (1634) pasando, por supuesto, y como hito fundamental, por La Dorotea (1632), sin olvidar la Arcadia (1598)" 53 .

Y, sin duda, otro rasgo característico del Siglo de Oro, la sátira política, nos ayudaría a realizar una posible lectura o interpretación de esta obra. Recordemos que esta adaptación fue escrita por Bergamín en 1953 y que nuestro dramaturgo ironizaba sobre la posibilidad de estrenarla en Madrid. En el sentir y pensamiento bergaminianos los "gatos" no solo serían los nacidos en la capital de España, sino los partidarios del gobierno de Franco, en clara oposición a las "liebres", los republicanos defensores de un inquirir y dar ideas "libremente". El concepto de "ideas liebres" cobra aquí un nuevo matiz, pues mientras en Tanto tienes los espectadores reac-

53 Ibidem, pp. 41-42. 
cionarios no querían, a su pesar, que les dieran "gato por liebre" (TT, p. 58), en esta pieza se critica que los gatos madrileńos vean cómo su amada Zapaquilda es vendida al mejor oro, el americano, en clara referencia satírica a la apertura de relaciones con el régimen de Franco que Estados Unidos inició en 1947 y que desembocaría en la firma del Tratado de Madrid el 26 de septiembre de $1953^{54}$. El desencanto de los exiliados, al comprobar que su regreso resulta imposible y al ver consumada la "traición" de las fuerzas aliadas, resulta comprensible.

\section{DONDE UNA VOZ SE APAGA OTRA SE ENCIENDE}

En 1952 escribe Donde una voz se apaga otra se enciende, texto inédito que creíamos perdido y del que nos ha llegado la versión francesa, Echo où es-tu, a través del profesor Yver Roullière. Tal como comentábamos, en el texto de 1954 de las "Acotaciones a Medea” aparecía citada esta obra junto con Los tejados de Madrid y otras de las que solo tenemos en la actualidad su título -como La San Bartolomé y Sor Abelardo- bajo el nombre de La voz de Eco.

Ignoramos a quién se debe esta traducción de Donde una voz se apaga otra se enciende bajo el título francés de Echo où es-tu?, aunque seguramente correspondería a la versión que se radió en Francia el 24 de marzo de 1957, tal y como aparece documentado en la base de datos del INA ${ }^{55}$. Con toda probabilidad puede ser obra de Alice Alhwailer, a quien debemos otras versiones en francés de obras dramáticas de José Bergamín por esos años. Entre ellas tenemos el primer acto de Melusina y el espejo (Mélusine et le miroir), editada en la revista Soleil, La hija de Dios (La fille de Dieu) en Lettres française; y Médée l'enchanteresse, en Esprit. Su relación con Bergamín data de la guerra civil, cuando con su hermano Rolland-

54 Idea ya apuntada en Ma Teresa Santa María Fernández, "El teatro peregrino de Bergamín”, en José Bergamín. El laberinto de la palabra, ed. Rafael Bonilla Cerezo, Córdoba, Diputación de Córdoba, 2008, pp. 182-183.

55 Iván López Cabello et Yves Roullière (eds.), José Bergamín et la France. Actes de la journée d'étude réalisée à Nanterre le 23 mai 2008. Suivi de Entretiens avec un fantôme. Les confidences de l'écrivain espagnol José Bergamin recueillies par André Camp, Nanterre, Université de Paris Ouest Nanterre La Défense, 2011, p. 259. 
Simon traduce algunos poemas y artículos del escritor exiliado ${ }^{56}$.

$\mathrm{Su}$ trato fue frecuente y epistolar durante el exilio por tierras americanas, pues la escribe desde México, el 4 de septiembre de 1946, o desde Montevideo, el 5 de abril de 1951. En dichas cartas le habla de la posible traducción de algunas de esas obras mencionadas. Concretamente, cita La niña guerrillera, La hija de Dios, Melusina y el espejo y alude a una comedia que está preparando en 1946 "para Madeleine Ozeray que quiere llevarla consigo para cuando vuelva a París". No sabemos si se trata de Donde una voz se apaga o de Melusina y el espejo, obra que publica entre 1949 y 1952 en Montevideo. Aunque seguramente sea la que ahora nos ocupa, pues en una carta a Jean Cassou, fechada el 4 de agosto de 1952, comenta: "Y sigo siempre con mi teatro imposible: Eco, Medea y la Beatriz de ¿A dónde iré que no tiemble?".

Yves Roullière aduce varias razones que llevaron a la ruptura de esa relación de amistad. Por ejemplo, las dudas de Bergamín sobre la calidad de sus traducciones, tal y como comenta en la citada carta a Jean Cassou, del 4 de agosto de 1952, a propósito de su Melusina:

Me envió nuestra amiga Alice (creo que seguís siendo amigos, a pesar de todo) su versión completa de MELUSINA; me gustaría tu impresión (en secreto). Yo creo que mi texto se apaga; pero no por culpa de la traductora sino de mi español, en este caso, tan superficialmente intransferible. Pero yo no puedo juzgarlo en francés. Por eso te pido tu impresión de conocedor del caso por ambos lados. Porque recibo opiniones contradictorias.

A ese distanciamiento se suma su divorcio de Dominique Ahrweiler, su posterior boda con el escritor Pierre Gascar y, como veremos luego, el estreno de La hija de Dios en 1960, obra premiada en el Festival de Arras pero que fue representada sin el permiso de José Bergamín.

El texto mecanografiado y en francés consta de tres jornadas o actos con un epílogo. Junto con el dúo protagonista aparecen otros personajes: Hélène, Tiresias, Julie, Le pere Xavier, Suzanne, Isabelle, Mere Angelique

56 Información que debo y agradezco a Yves Roullière, quien me ha proporcionado también no solo el texto de Donde una voz se apaga, sino todos los datos sobre la relación entre Alice Ahrweiler y Bergamín que comentamos en estas páginas. 
(la mère supérieure), Soeur Epiphanie (une vieille religieuse), Soeur Sílice (une autre religieuse), Liriope (mère de Narcisse), Nise, Lidia y "Un couple de vieux paysans". La acción del primer acto y del Epílogo se sitúa en "Un collage religieux de jeunes filles. C'est le printemps" (p. 1), mientras que el segundo y tercero transcurren en la casa de madame Lirope. Entre los dos primeros actos no pasa más de un día, mientras que del segundo al tercero habrá transcurrido un año - de primavera a primavera- y el epílogo acabará, a su vez, el invierno siguiente al que inició la obra.

Podemos observar en los tres actos de la pieza el esquema clásico de planteamiento-nudo-desenlace y estamos de nuevo ante una obra que retoma y versiona un mito o trama anteriores: el de Narciso y Eco, ubicándolo en época contemporánea y dentro del gusto por los juegos de palabras y los aforismos tan característicos de nuestro escritor. La obra coincide en muchos aspectos con otra anterior de José Bergamín, Melusina y el espejo o Una mujer con tres almas o Porqué tiene cuernos el diablo, pues ambas desarrollan un cuento dentro de la historia, en ellas cobra vital importancia el espejo como elemento de la trama argumental, se enfatiza en el engaño que nos proporcionan nuestros sentidos o conservan ese aire inmortal, de historia que se repite, siempre igual y siempre diferente, sobre el que giran ambas piezas y que relaciona a sendas protagonistas con las leyendas y relatos populares. Porque en Donde una voz se apaga no solo la protagonista nos recuerda a la ninfa Eco, sino que la presencia fantasmal de "Oeil Bleu" nos sumerge en todo tipo de cuentos del folklore europeo y la aparición del viejo Tiresias nos evoca la de varias tragedias griegas. Por otro lado, en ambas obras, José Bergamín desarrolla un argumento donde cobra relevancia las metamorfosis al estilo de Ovidio. Así si en Melusina y el espejo nos encontramos con la transformación final de sus personajes principales:

\author{
ARLEQUÍN. (Al público) \\ Público: con tu favor, \\ Melusina está en su estrella; \\ bosque enredado por ella \\ se hizo el Diablo enredador; \\ Minutisa es una floral primer albor nacida: \\ y yo, espejo de la vida, \\ para hacerme tu conciencia,
}


voy a tomar la apariencia

de un arroyo en clara huida. (MYE: 266, vv. 1481-1490),

por su parte, en Donde una voz se apaga dicha transformación parece que no llega, que se estanca en el ámbito de lo sońado y presentido, idea que se confirma con ese final que vuelve al principio, como si fuera una historia que se repite cada cierto tiempo, que nunca tiene fin.

Encontramos en esta pieza muchos de los recursos dramáticos utilizados por José Bergamín en otras obras. En primer lugar, la aparición de la música, destacada y relevante para ayudar a conseguir la tensión dramática, tal y como se describe en las acotaciones. De esta forma, el sonido del harmonio y el coro de niñas se oye tanto en el Primer Acto como en el Tercero y Cuarto (p. 9, 23, 79 o 82 y 92). Al contrario que en otras obras suyas, no se especifica el título de la canción o música que se escucha, salvo la alusión, en el Primero, de que se trata del himno del Sagrado Corazón (p. 33). También aparece el sonido de una tiza sobre la pizarra o de una niña recitando una lección (p. 1), de puertas, voces y, sobre todo, el de las campanas en momentos culminantes de la acción, pues su sonido es la señal que se menciona en el mensaje recibido por el fantasma (p. 7), para que Eco se acerque al estanque en el Primer Acto (p. 23), mientras que en el Cuarto Acto será su sonido el que recuerde no solo dicha seńal, sino con el que finalice toda la obra (p. 93).

También son rasgos importantes dentro del teatro de Bergamín la utilización de juegos de palabras, como el que se forma entre "Madame Léliotrope ou Liotrope" (p. 8) con Liriope (p. 9), nombre real de la madre de Narciso y que hace mención a otro tipo de flor, lo que le vincula con la metamorfosis del propio protagonista pero también con una cita del Evangelio -los lirios del campo (p. 77) - que es otra constante en nuestro dramaturgo. Otro elemento recurrente es la aparición de aforismos, algunos muy vinculados con otros textos bergaminianos, como los relacionados con el diablo: "Toute me sagesse viene du temps, comme celle qu'on attribue au Diable" (p. 61) o "ECHO: (...) Vous dite des choses effrayantes. Oui, comme un devin! TIRESIAS: Comme un vieillard" (p. 67); o con el amor, "le mot le plus terrible que les hommes dient inventé", porque "qu'il nous sépare suitant quíl nos rapproche de Dieu" (p. 73) y "l'homme devrait marcher à quatre pattes pour dissimuler la pureté de 
son coeur"; o bien, relacionados con uno de los temas preferidos por el escritor exiliado, el tiempo: "Le vent comme le temps ne parle pas, mais il fait parler" (p. 64).

Por otro lado, cobran relevancia los intentos por hacer verosímiles los elementos del relato mítico en la época contemporánea, situación temporal que viene remarcada con objetos actuales como el teléfono o la radio (p. 79). Pero, sobre todo, la manera en que recoge los aspectos más relevantes del relato mítico sobre la historia de Narciso y Eco, tal y como se recoge en el libro III de Las metamorfosis de Ovidio (versos 339-510), como la intervención del adivino Tiresias, la capacidad de Eco para reproducir y articular cualquiera de las voces que escucha o el gusto de Narciso por contemplarse en los múltiples espejos que se encuentran en la mansión, el citado nombre de la madre de Narciso, Liriope, y la transformación de este en otra flor, así como la aparición de los disfraces de ninfas, el estanque y el bosque, las alusiones a los cazadores y a sus cuentos.

Además, como en otras piezas dramáticas bergaminianas aparece alusiones o citas a otros autores, como el poema "Ofelia" de Rimbaud (p. 7) o "La muerte de Narciso" de Lezama Lima y la historia de Sigfrido recogido en Flor de leyendas por Casona. Todo ello contribuye a dar el aire de historia atemporal, rica en evocaciones y detalles de la literatura universal.

\section{RECEPCIÓN DE LA OBRA DRAMÁTICA EN FRANCIA}

Dentro de las representaciones del teatro de Bergamín en Francia, nos encontramos con tres situaciones diferentes. En primer lugar, aquellas obras que quedaron como meros proyectos, sin que se concretaran en ninguna representación. El dramaturgo exiliado, ya en América, intentó encontrar alguna compañía, director o actor que llevara al escenario algunas de sus piezas en el país galo. En su correspondencia con diferentes amigos y conocidos franceses se refiere a ese interés. Así, en una carta a André Malraux, firmada en México el 4 de septiembre de 1946, le explica:

Yo creo que mi posible estancia en París podría facilitarse con alguna representación teatral o por radio de cualquier pieza mía. Hay dos cosas que podrían interesar: La niña guerrillera y La hija de Dios. 
También estoy escribiendo una comedia para Madelaine Ozeray, que quiere llevársela a París cuando vuelva.

Y en otra a Alice Ahrweiler, fechada en Montevideo el 5 de abril de 1951, comenta la posibilidad de que María Casares interprete a su Medea.

En segundo lugar, algunos fragmentos de sus piezas teatrales -o la obra entera, en algunos casos- fueron representados o llevados a la radio o a la televisión. Tal es el caso de la radiación de Médée, l'enchanteresse: Une visite de noces, el 25 de marzo de 1956, Écho, où es-tu? (Donde una voz se apaga), el 24 de marzo de 1957, o L'impromptu d'Hamlet que junto con La dame fantôme de Calderón fue difundida el 18 de diciembre de $1960^{57}$. Asimismo, Michel Mitrani realiza dos reportajes televisivos para la ORTF (Office National de Radioduffusion Télévision Française). En el primero, emitido por primera vez el 24 de marzo de 1970, y titulado Reportages sur un squelette, ou Masques et Bergamasques, "se emite una selección de su obra dramática: Medea, la encantadora, Melusina y el espejo y Los tejados de Madrid. Todo ello bajo los auspicios de Malraux"58. En cambio, Les anges exterminés se emitirá el 15 de enero de 1968, también por el segundo canal de la ORTF. Aparecerán diversas escenas de obras de teatro españolas y comentarios de Bergamín sobre ellas o sobre la vida en España en ese momento.

Por último, el 11 de junio de 1960 se estrenó La hija de Dios en el Palais Saint-Vaast de Arras y dentro del "Festival du Jeune Théâtre populaire". La compañía de Edmond Tapiz la representaría en la traducción francesa de Alice Gascar, nuevo nombre de casada de Alice Arhweiler, quien ya publicó algunos fragmentos de la pieza en francés dentro de distintos números de Lettres françaises (4, 11 y 18 de enero de 1951), con motivo de la intervención del propio autor en un acto de homenaje del Comité National des Escrivains en enero de 1951. Tenemos pocos datos de ese estreno, aunque sabemos que no contó con la aprobación expresa de Bergamín y fue uno de los motivos de ruptura definitiva con Alice Arhweiler. Sin embargo, el periódico Le Monde se hizo eco no solo del certamen y de las tres piezas contra las que competiría -L'Illusion comique, de Corneille, Beaucoup de bruit pour rien, de Shakespeare y L'Ex-Napoléon, de

57 Iván López Cabello e Yves Roullière (eds.), op.cit., p. 259.

58 Gonzalo Penalva, op. cit., p. 237. 
Nino Francket Paul Gilson-, sino que su corresponsal, Claude Sarrate, da noticia de esa representación y aporta algún dato más. Así sabemos por el artículo que la actriz Mary Mergey interpretó el papel de Teodora de forma sobria, que el coro estaba compuesta por mujeres con velo negro y que se trata de una "Pièce âpre, d'une belle qualité d'écriture, qui devait trouver l'autre soir sur une scène de plein air, balayée par la pluie et par de forts vents coulis, sa juste expression tragique". Algunos de los fragmentos de esta crónica fueron traducidos y reproducidos en la revista Primer Acto, donde se expone también el recelo de la cronista respecto a "si en nuestra época la forma adoptada por los antiguos encuentra todavía una resonancia, despierta nuevos ecos. Más interesante sería, sin duda, una expresión teatral nueva, mejor adaptadas a nuestra sensibilidad de hoy" ${ }^{59}$.

\section{A MODO DE CONCLUSIÓN}

Como conclusión a la dramaturgia que Bergamín escribe o publica durante sus dos exilios en París, podemos destacar la variedad de temas y modelos que elige para sus obras. También resulta relevante la inspiración francesa en dos de ellas, La sangre de Antígona y Donde una voz se apaga; mientras que en las dos restantes, La cama, tumba del sueño y Los tejados de Madrid, se hace más presente e importante esa Espańa que, tan cerca y tan lejos, se le aparece durante su estancia en Francia. Por último, cabe destacar la importancia de ese periodo dentro de la producción dramática del escritor desterrado, pues a los títulos ya citados tendríamos que sumar otros proyectos o conatos de obras, perdidos en la actualidad. Un interés por el teatro que ya no volverá a mostrar desde su vuelta definitiva a España, en 1970, hasta su muerte, en agosto de 1983.

59 Primer Acto (1960), "Estreno en Arras de una obra espańola", Madrid, 15, p. 59. 